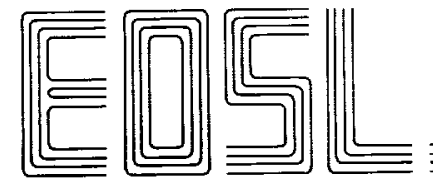

Electro-0ptic Systems Laboratory Department of Electrical and Computer Engineering

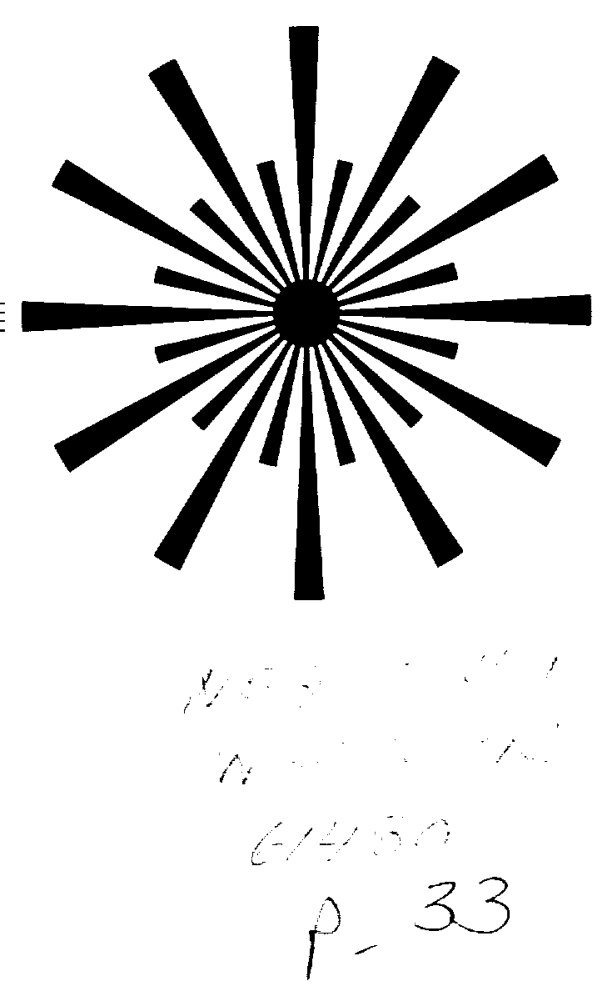

\title{
Ranging Performance of Satellite Laser Altimeters
}

Chester S. Gardner

EOSL No. 92-002 - January 1992

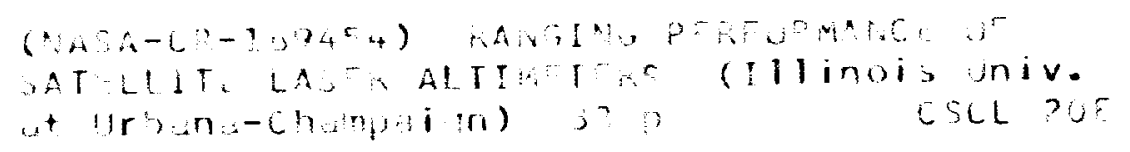

33/3t: orolas

University of Illinois at Urbana-Champaign 
$\ldots$

1 
UILU-ENG-92-2547

\title{
RANGING PERFORMANCE OF SATELLITE LASER ALTIMETERS
}

by

Chester S. Gardner

EOSL No. 92-001

\author{
Technical Report \\ January 1992
}

Supported by Grant

NASA NSG-5049

\section{NATIONAL AERONAUTICS AND SPACE ADMINISTRATION GODDARD SPACE FLIGHT CENTER \\ GREENBELT, MD 20771}

ELECTRO-OPTIC SYSTEMS LABORATORY

DEPARTMENT OF ELECTRICAL AND COMPUTER ENGINEERING

COLLEGE OF ENGINEERING

UNIVERSITY OF ILLINOIS

URBANA, ILLINOIS 61801 


\title{
Ranging Performance of Satellite Laser Altimeters
}

\author{
by \\ Chester S. Gardner \\ Department of Electrical and Computer Engineering \\ University of Illinois at Urbana-Champaign \\ 1406 West Green Street - Everitt Laboratory \\ Urbana, Il 61801 \\ (217) 333-4682
}

\begin{abstract}
Topographic mapping of the earth, moon and planets can be accomplished with high resolution and accuracy using satellite laser altimeters. These systems employ nanosecond laser pulses and microradian beam divergences to achieve submeter vertical range resolution from orbital altitudes of several hundred kilometers. In this paper we develop detailed expressions for the range and pulse width measurement accuracies and use the results to evaluate the ranging performances of several satellite laser altimeters currently under development by NASA for launch during the next decade. Our analysis includes the effects of the target surface characteristics, spacecraft pointing jitter and waveform digitizer characteristics. The results show that ranging accuracy is critically dependent on the pointing accuracy and stability of the altimeter especially over high relief terrain where surface slopes are large. At typical orbital altitudes of several hundred kilometers, single-shot accuracies of a few centimeters can be achieved only when the pointing jitter is on the order of $10 \mu \mathrm{rad}$ or less.
\end{abstract}





\section{TABLE OF CONTENTS}
1. INTRODUCTION

2. ALTIMETER RECEIVER MODEL

3. GROUND TARGET MODEL AND LINK EQUATION …....................................... 5

4. MEAN PROPAGATION DELAY AND RMS PULSE WIDTH …..........................

5. RANGE AND PULSE WIDTH ERRORS

11

6. SURFACE SLOPE MEASUREMENTS ................................................................ 14

7. BACKGROUND NOISE, THERMAL NOISE, QUANTIZATION NOISE AND SAMPLING EFFECTS

8. EXPECTED PERFORMANCE CAPABILITIES OF SEVERAL SATELLITE LASER ALTIMETER SYSTEMS

9. CONCLUSIONS 



\section{INTRODUCTION}

Topographic mapping of the earth, moon and planets can be accomplished with high resolution and accuracy using satellite laser altimeters. These systems typically are pointed at nadir and function by measuring the round-trip propagation time of short laser pulses that are reflected from land, water or ice surfaces. The reflected laser pulses are distorted by surface variations within the footprint so that the shapes of the received waveforms also contain important information about surface roughness, slope and reflectivity. Meter or even centimeter vertical range resolution is possible from orbital altitudes of several hundred kilometers by employing gain switched solid state lasers with pulse lengths of 1-10 ns (0.3-3 m). Horizontal resolution is a function of the laser footprint diameter and pulse rate. Footprint diameters of several tens to several hundreds of meters and kilohertz pulse rates are readily achieved with current laser technology.

Laser altimetry, especially from aircraft, has a long history of development and application. The first spaceborne altimeters were ruby laser systems flown on the APOLLO 15, 16 and 17 missions to the moon [Kaula et al., 1974]. During the past two decades numerous airborne system have been developed to measure geologic features such as volcanoes [Garvin et al., 1991], ice sheet topography [Bufton et al., 1982] and sea state [Abshire and McGarry, 1987; Tsai and Gardner, 1982]. Bufton [1989] provides an excellent overview of the laser altimetry field while Bufton et al. [1991] describe recent technology advances that are yielding significant improvements in the accuracy and resolution of airborne systems.

Several satellite altimeters are now under development at NASA, to study the earth, moon and Mars. These include the Geoscience Laser Ranging System (GLRS) which is being developed for the Earth Observing System [Cohen et al., 1987], the Mars Observer Laser Altimeter (MOLA) which will be launched in 1992 [Abshire et al., 1991], the Lidar In-Space Technology Experiment (LITE) planned for launch on the shuttle in late 1993 [Couch et al., 1991], the Lunar Observer Laser Altimeter (LOLA) and the Topographic Mapping Laser Altimeter (TMLA) which is being developed as a small dedicated Earth Probe Class Satellite 
[Harding et al., 1991] . All of these instruments will to some degree, record information about the reflected pulse shape as well as the standard time-of-flight data. The use of laser waveform data in topographic applications has not been explored thoroughly. Gardner [1982] and Tsai and Gardner [1982] have studied the effects of the surface profile and sea state on the shapes and widths of ground and ocean reflected laser pulses. In this paper we extend their results to analyze the performance of satellite laser ranging systems. We develop detailed expressions for the range and pulse width measurement accuracies and use these results to evaluate the expected performances of the LITE, TMLA, GLRS, MOLA and LOLA altimeters. Our analysis includes the effects of the target surface characteristics, spacecraft pointing jitter, and waveform digitizer characteristics.

\section{ALTIMETER RECEIVER MODEL}

The geometry of the laser altimeter and ground target is illustrated in Fig. 1. We assume the ground target is diffuse and there are no specular reflections. Therefore, the analysis applies to reflections from land or snow but does not apply to reflections from water or ice. The detector model is illustrated in Fig. 2. A portion of the reflected optical pulse $p(t)$ is collected by the receiving telescope and focused onto a detector. The detector is modeled as an ideal detector followed by a linear filter with an impulse response given by $h(t)$. The detector output current $\mathrm{i}(\mathrm{t})$ is sampled and quantized by an A/D converter and then processed by a range computer which computes the signal level, pulse propagation delay and pulse width.

The detected signal is contaminated by several types of noise which effect the accuracies of the computed pulse parameters. The optical signal is affected by both photon noise and speckle noise while the detector output will be contaminated by thermal noise and perhaps multiplication noise if the detector is an avalanche photodiode. Finally, the quantized signal at the output of the A/D converter will be contaminated by quantization noise. The effects of all these noise sources on the performance of the laser altimeter is considered in the following sections. 


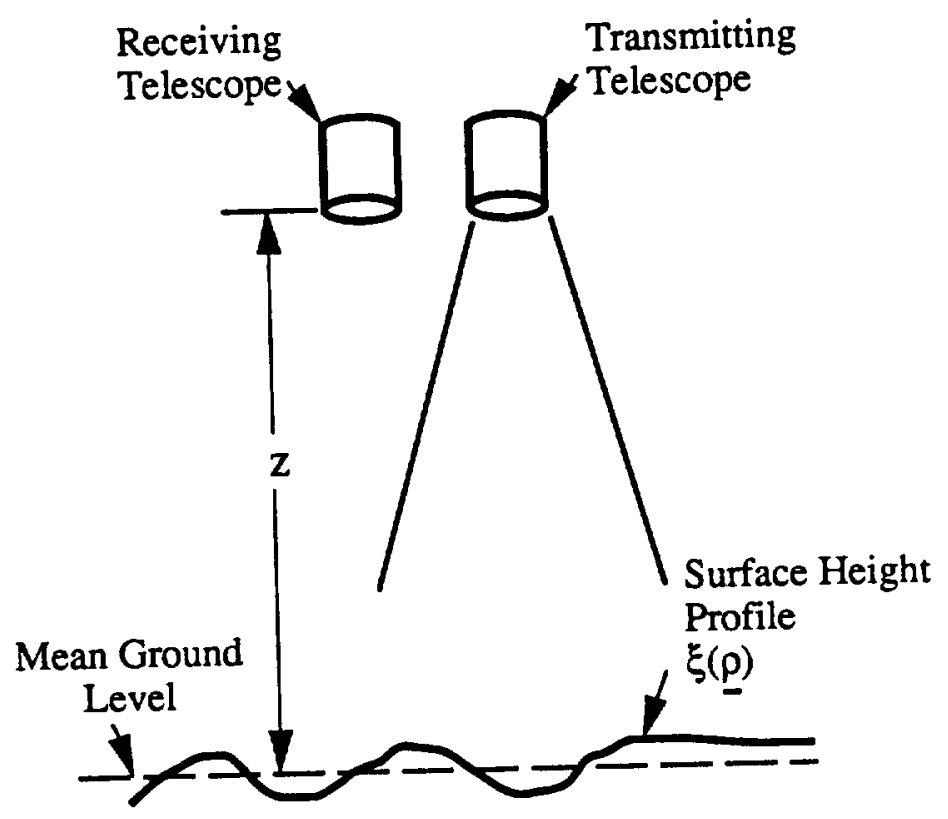

Ground Target

Figure 1. Geometry of the laser altimeter and ground target for nadir pointing.

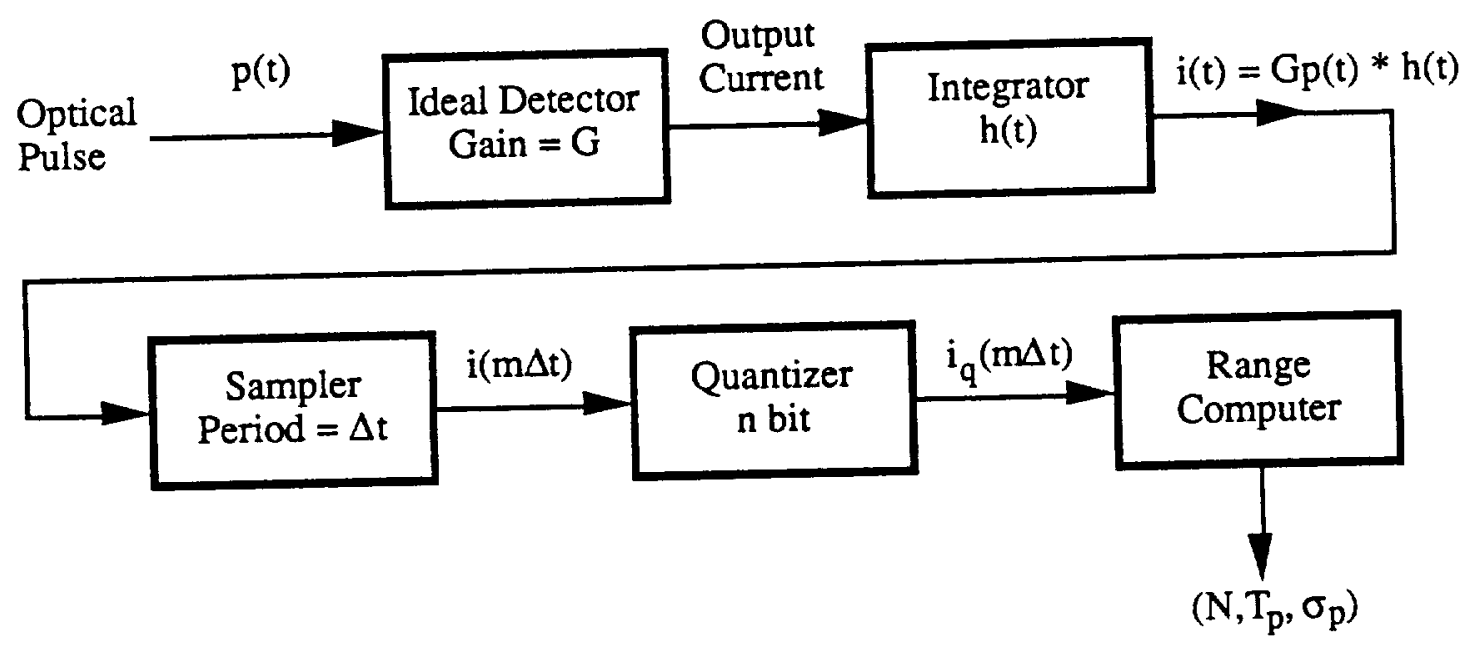

Figure 2. Detector model for the laser altimeter.

Ranging performance is influenced to a great extent by pulse shape, signal level and the algorithms used to compute the pulse delay. Unfortunately, minimum mean-square error (mmse) estimation techniques cannot be used with laser altimeters because the received pulse shape depends upon the surface profile and cannot be predicted a priori. The most effective technique for estimating range when the pulse shape is unknown is to compute the centroid of the received 
pulse. The performance of this estimator is proportional to the rms pulse width and is inversely proportional to the square root of the signal photon count. In this paper we are primarily interested in deriving theoretical expressions for the pulse centroid time $T_{p}$, the rms pulse width $\sigma_{\mathrm{p}}$ and the pulse photon count $\mathrm{N}$. These three parameters are functions of the temporal moments of the pulse and are defined as follows

$$
\begin{aligned}
& N=\int_{0}^{\infty} p(t) d t \\
& T_{p}=\frac{1}{N} \int_{0}^{\infty} t p(t) d t \\
& \sigma_{p}^{2}=\frac{1}{N} \int_{0}^{\infty}\left(t-T_{p}\right)^{2} p(t) d t
\end{aligned}
$$

where $p(t)$ is the expected received pulse shape, i.e. photon count rate (photons/sec). Of course, the receiver computes estimates of $N, T_{p}$ and $\sigma_{p}{ }^{2}$ from measurements of the detector output current $i(t)$.

If we assume that the detector bandwidth is much larger than the signal bandwidth, then $h(t)$ can be modeled as an ideal integrator

$$
h(t)= \begin{cases}e / \Delta t & |t| \leq \Delta t / 2 \\ 0 & \text { otherwise }\end{cases}
$$

where $\mathrm{e}$ is the electron charge and $\Delta t$ is the sampling interval or range bin length of the $A / D$ converter. The expected output current of the detector is

$$
\begin{aligned}
& E[i(t)]=G p(t)^{*} h(t)=G \int_{t-\Delta t / 2}^{t+\Delta t / 2} \frac{e}{\Delta t} p(t) d \tau=G e p(t) \\
& G=\text { detector gain. }
\end{aligned}
$$


Since $E(i)$ is proportional to $p(t)$, the parameters $N, T_{p}$ and $\sigma_{p}^{2}$ can be computed from (1)-(3) with $p(t)$ replaced by $i(t)$

$$
\begin{aligned}
& N=\frac{1}{G e} \int_{0}^{\infty} i(t) d t \\
& T_{p}=\frac{1}{G e N} \int_{0}^{\infty} t i(t) d t \\
& \sigma_{p}^{2}=\frac{1}{G e N} \int_{0}^{\infty}\left(t-T_{p}\right)^{2} i(t) d t
\end{aligned}
$$

In subsequent sections we derive theoretical expressions for the means and variances of these parameters.

\section{GROUND TARGET MODEL AND LINK EQUATION}

Since the ground target is a diffuse reflector, the statistics of the reflected signal are identical to statistics for fully developed speckle. The signal amplitude is a circular complex Gaussian process and the signal intensity obeys negative exponential statistics. The mean and variance of the total detected photon count are given by [Gardner, 1982]

$$
\begin{aligned}
& <N>=E\left[\frac{1}{G e} \int_{0}^{\infty} i(t) d t\right]=T_{a} 2 \frac{\eta E}{h v} \frac{A}{\pi r^{2}} \beta(\phi) \\
& \operatorname{Var}(N)=F<N>+\langle N\rangle^{2} / K_{s} \\
& K_{s}=\pi A\left(\frac{2 \tan \theta_{T}}{\lambda}\right)^{2}
\end{aligned}
$$


where

$$
\begin{aligned}
F & =\text { excess noise factor of the detector } \\
T_{a} & =1 \text {-way atmospheric transmittance } \\
\eta & =\text { detector quantum efficiency } \\
E & =\text { total transmitted pulse energy (Joules) } \\
h v & =\text { photon energy (Joules) } \\
A & =\text { receiver aperture area }\left(\mathrm{m}^{2}\right) \\
r & =\text { z/cos } \phi=\text { ground target range (m) } \\
z & =\text { altimeter altitude (m) } \\
\phi & =\text { nadir angle of laser beam } \\
\beta(\phi) & =\text { diffuse reflectivity of the target } \\
\theta_{\mathrm{T}} & =\text { laser beam divergence, HW @ } \mathrm{e}^{-1 / 2}(\mathrm{rad}) \\
\lambda & =\text { laser pulse wavelength (m). }
\end{aligned}
$$

$\mathrm{K}_{\mathrm{s}}$ is the ratio of the receiver area to the speckle correlation area and is usually called the speckle signal-to-noise ratio. The speckle correlation area is inversely proportional to the area of the laser footprint. Typically, $\mathrm{K}_{\mathrm{s}}$ is on the order of $10^{4}-10^{5}$ and $<\mathrm{N}>$ is on the order of $10^{3}-10^{4}$.

The excess noise factor $F$ is equal 1 for photomultiplier tube (PMT) detectors and between 3 and 7 for avalanche photodetectors (APD). In general, the altimeter will not always be pointed at nadir. The system geometry for arbitrary nadir angles is illustrated in Fig. 3. The coordinate system is defined by the optical axis of the altimeter and the line drawn from the altimeter to the center of the earth. The nadir angle $\phi$ is the angle between the optical axis and center line. The center line is defined as the $z$ axis. The 2-D surface profile is described by the function $\xi(\Omega)$ where $R=(x, y)$ is the horizontal position vector on the ground which is normal to the $z$-axis. The surface profile within the laser footprint is modeled as

$$
\xi(\rho)=\xi_{0}+\underline{S} \cdot \underline{Q}+\Delta \xi(\rho)
$$


where $\xi_{0}$ is a constant offset, $\underline{S}$ is the mean surface slope within the footprint and $\Delta \xi$ is the surface roughness. The model given by (12) differentiates the linear variation in surface height, $\xi_{\mathrm{o}}+\underline{S} \cdot Q$, from the quasi-random surface roughness variations $\Delta \xi$. By defining the origin of the coordinate system as the intersection point of the center line and the earth's surface we have $\xi_{0}=0$ and

$$
\xi(x, y)=x \tan S_{\|}+y \tan S_{\perp}+\Delta \xi(x, y)
$$

where $S_{\|}$is the surface slope parallel to the nadir direction and $S_{\perp}$ is the surface slope normal to the nadir direction. Similarly, we define $\Delta \phi_{\|}$and $\Delta \phi_{\perp}$ as the orthogonal components of the pointing jitter, parallel and normal to the nadir direction.

\section{MEAN PROPAGATION DELAY AND RMS PULSE WIDTH}

Expressions for the mean pulse propagation delay and rms width can be derived using the same assumptions and the approach employed by Gardner [1982]. If we assume the laser beam cross-section is Gaussian (TEM ${ }_{\infty}$ mode), then for the geometry illustrated in Fig. 3, the mean pulse delay is

$E\left(T_{p} \mid \Delta \phi_{\|}, \Delta \phi_{\perp}\right)=\frac{2 z\left(1+\tan ^{2} \theta_{T}\right)}{c \cos \phi} \frac{\left[1+\tan ^{2}\left(\phi+\Delta \phi_{\|}\right)+\tan ^{2} \Delta \phi_{\perp}\right]^{1 / 2}}{\left[1-\tan \left(\phi+\Delta \phi_{\|}\right) \tan S_{\|}-\tan \Delta \phi_{\perp} \tan S_{\perp}\right]} \frac{\cos \left(\phi+S_{\|}\right)}{\cos S_{\|}}$

and

$$
\begin{aligned}
\mathrm{E}\left(\mathrm{T}_{\mathrm{p}}\right)= & \frac{2 z\left(1+\tan ^{2} \theta_{\mathrm{T}}\right)}{\mathrm{c} \cos \phi}\left[1+\left(1+2 \tan ^{2}\left(\phi+\mathrm{S}_{\|}\right)\right) \frac{\operatorname{Var}\left(\Delta \phi_{\|}\right)}{2}\right. \\
& \left.+\cos ^{2} \phi\left(1+\frac{2 \tan ^{2} S_{\perp} \cos ^{2} S_{\|}}{\cos ^{2}\left(\phi+S_{\|}\right)}\right) \frac{\operatorname{Var}\left(\Delta \phi_{\perp}\right)}{2}\right]
\end{aligned}
$$




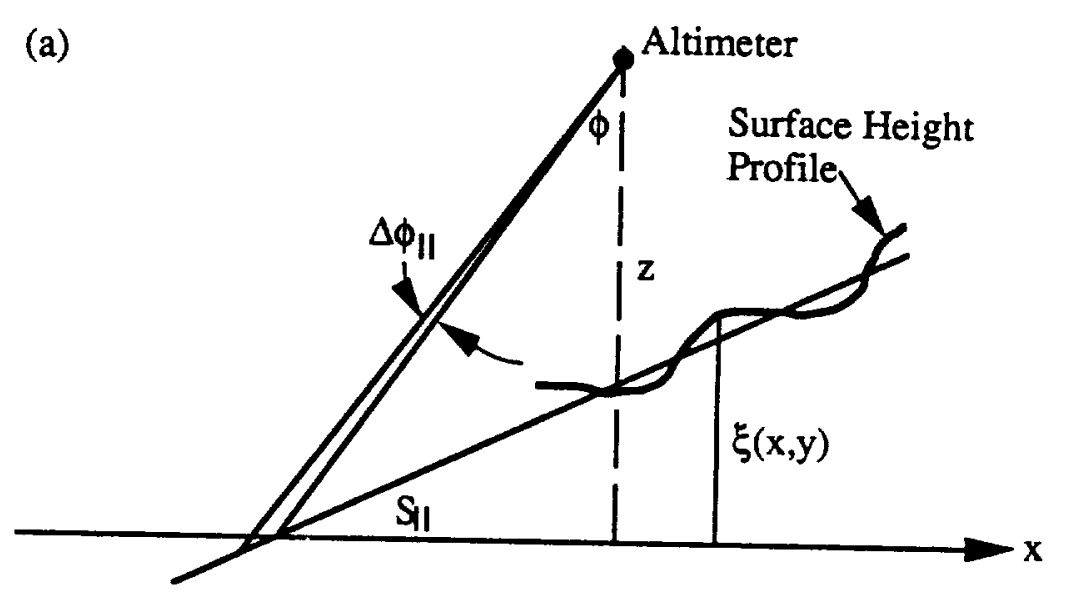

(b)

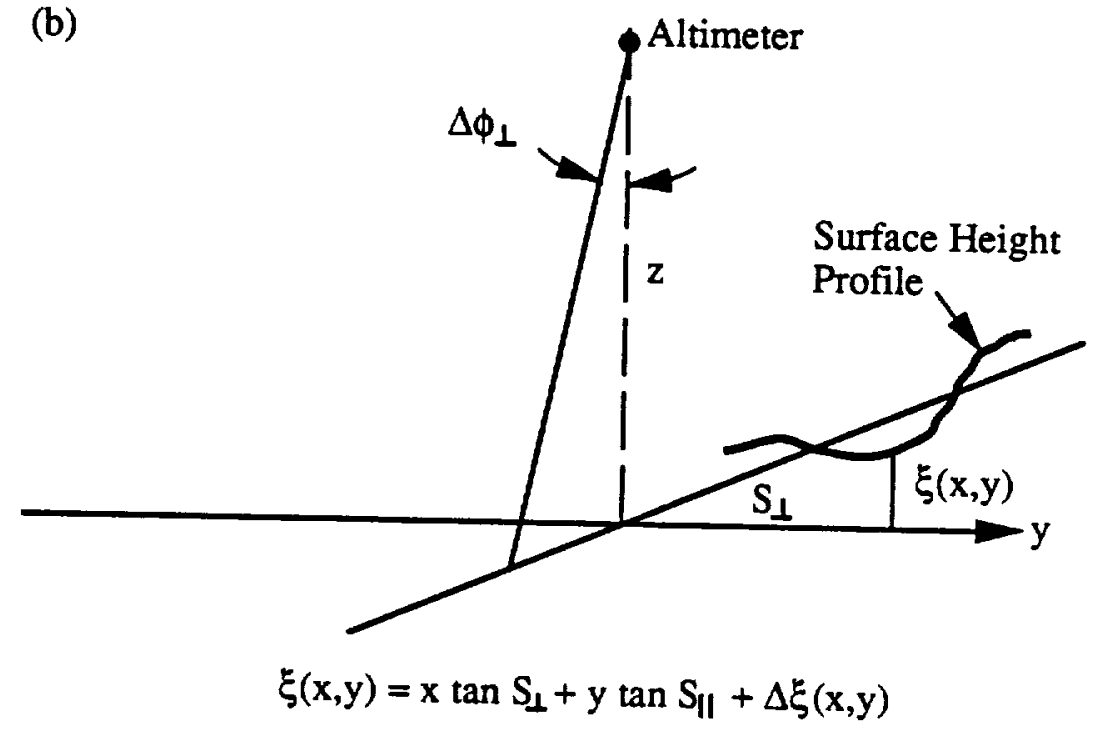

Figure 3. Generalized geometry for the laser altimeter and ground target. $\xi(x, y)$ is the surface height.

where

$$
\begin{aligned}
c(\phi) & =\text { effective velocity of light }(\mathrm{m} / \mathrm{s}) \\
S_{\|} & =\text {surface slope parallel to nadir direction } \\
S_{\perp} & =\text { surface slope normal to nadir direction } \\
\Delta \phi_{\|} & =\text {pointing error parallel to nadir direction } \\
\Delta \phi_{\perp} & =\text { pointing error normal to nadir direction. }
\end{aligned}
$$


The effective velocity of light depends on the laser wavelength, nadir angle and surface meteorological conditions. The additional roundtrip propagation delay introduced by the earth's atmosphere is approximately $16 \mathrm{~ns}(4.7 \mathrm{~m})$ at nadir and is proportional to $1 / \cos \phi$ [Gardner, 1977].

The expected propagation delay given by (15) is composed of three terms. The $2 z /(\mathrm{c} \cos \phi)$ term represents the roundtrip propagation delay along the center of the laser beam. The term $2 z$ $\tan ^{2} \theta_{T} /(c \cos \phi)$ is the additional delay resulting from the phase front curvature of the diverging laser beam. Finally, the terms involving $\operatorname{Var}\left(\Delta \phi_{\| 1}\right)$ and $\operatorname{Var}\left(\Delta \phi_{\perp}\right)$ are biases caused by pointing jitter. Equation (15) was derived by expanding Eq. (14) for the conditional mean delay in a power series in terms of $\Delta \phi_{\perp}$ and $\Delta \phi_{\|}$, retaining the terms out to second order in both $\Delta \phi_{\perp}$ and $\Delta \phi_{\|}$and by assuming the orthogonal components of the pointing jitter are statistically independent.

For nadir pointing the range biases, (i.e., $\mathrm{cT}_{\mathrm{p}} / 2$ ) introduced by beam curvature and pointing jitter are approximately

Beam curvature range bias $\simeq \mathrm{z} \tan ^{2} \theta_{\mathrm{T}}$

Pointing jitter range bias $\simeq \mathrm{z} \operatorname{Var}(\Delta \phi)$

The pointing jitter bias dominates whenever the rms jitter exceeds the beam divergence. For an altimeter altitude of $1000 \mathrm{~km}$ and an rms pointing jitter of $10 \mu \mathrm{rad}$, the range bias caused by pointing jitter is only $0.1 \mathrm{~mm}$. For a beam divergence of $64 \mu \mathrm{rad} \mathrm{HW} @ \mathrm{e}^{-1 / 2}(150 \mu \mathrm{rad}$ FWHM), the range bias caused by beam curvature is $4 \mathrm{~mm}$.

An expression for the mean-square pulse width can also be derived for the geometry illustrated in Fig. 3 by following the approach of Gardner [1982] 
Table 1 Typical Values for Pulse Broadening Contributions

\begin{tabular}{|c|c|c|}
\hline Source & Simplified Formula & Value* \\
\hline System effects & $\frac{c}{2}\left(\sigma_{\ell}^{2}+\sigma_{h}^{2}\right)^{1 / 2}$ & $\sim 1 \mathrm{~m} @ \sigma_{\mathrm{h}} \simeq \sigma_{l}=5 \mathrm{~ns}$ \\
\hline Surface roughness & $\operatorname{Std}(\Delta \xi)$ & $0.01-10 \mathrm{~m}$ \\
\hline Beam curvature & $\mathrm{z} \theta \mathrm{T}^{2}$ & $<0.01 \mathrm{~m} @ \mathrm{z}=1000 \mathrm{~km}$ \\
\hline Nadir angle effects & $z \theta_{T} \tan \phi$ & $\begin{array}{l}1.1 \mathrm{~m} @ \phi=1^{\circ} \\
5.5 \mathrm{~m} @ \phi=5^{\circ} \\
12 \mathrm{~m} @ \phi=10^{\circ}\end{array}$ \\
\hline Surface slope & $z \theta_{\mathrm{T}} \tan \overline{\mathrm{S}}$ & $\begin{array}{l}1.1 \mathrm{~m} @ S=1^{\circ} \\
5.5 \mathrm{~m} @ S=5^{\circ} \\
12 \mathrm{~m} @ S=10^{\circ} \\
37 \mathrm{~m} @ S=30^{\circ}\end{array}$ \\
\hline
\end{tabular}

*All values were computed assuming $z=1000 \mathrm{~km}$ and $\theta_{\mathrm{T}}=64 \mu \mathrm{rad}$ (i.e., $150 \mu \mathrm{rad} \mathrm{FWHM}$ )

$$
\begin{aligned}
& E\left(\sigma_{\mathrm{p}}^{2}\right)=\quad\left(\sigma_{\mathrm{l}}^{2}+\sigma_{\mathrm{h}}^{2}\right)+\frac{4 \operatorname{Var}(\Delta \xi) \cos ^{2} S_{\|}}{\mathrm{c}^{2} \cos ^{2}\left(\phi+S_{\|}\right)} \\
& \quad \text { (system effects) } \quad \text { (surface roughness effects) } \\
& +\frac{4 \mathrm{z}^{2} \tan ^{2} \theta_{\mathrm{T}}}{\mathrm{c}^{2} \cos ^{2} \phi}\left[\tan ^{2} \theta_{\mathrm{T}}+\tan ^{2}\left(\phi+S_{\|}\right)+\frac{\tan ^{2} S_{\perp} \cos ^{2} S_{\|}}{\cos ^{2}\left(\phi+S_{\|}\right)}\right], \\
& \text {(beam curvature effects) (nadir angle and surface slope effects) }
\end{aligned}
$$

where

$$
\begin{aligned}
& \sigma_{\ell}=\text { rms laser pulse width (s) } \\
& \sigma_{\mathrm{h}}=\text { rms width of receiver impulse response (s). }
\end{aligned}
$$

The system contributions to the width of the received pulse include the widths of the transmitted pulse and receiver impulse response. For wide bandwidth receivers which employ A/D converters to sample the detected signal, $\sigma_{h}=\Delta t / \sqrt{12}$ where $\Delta t$ is the sampling period. The 
received pulse is also broadened by the surface roughness and slope of the ground target and by the beam curvature. Typical values for the pulse broadening contributions (i.e., $\frac{c}{2} \sigma_{p}$ ) are listed in Table 1. Surface roughness, surface slope and nadir angle effects can be quite significant and may contribute several meters to several tens of meters to the pulse width.

\section{RANGE AND PULSE WIDTH ERRORS}

Photon noise, speckle noise and pointing jitter all contribute errors to the range and pulse width measurements. Again by generalizing the results of Gardner [1982], we obtain the following lengthy expression for the variance of the pulse propagation delay.

$$
\begin{aligned}
& \operatorname{Var}\left(\mathrm{T}_{\mathrm{p}}\right)=\frac{\mathrm{F}\left(\sigma_{\mathrm{l}}^{2}+\sigma_{\mathrm{h}}^{2}\right)}{\langle\mathrm{N}>}+\left(\frac{\mathrm{F}}{\langle\mathrm{N}>}+\frac{1}{\mathrm{~K}_{\mathrm{s}}}\right) \frac{4 \operatorname{Var}(\Delta \xi) \cos ^{2} \mathrm{~S}_{\|}}{\mathrm{c}^{2} \cos ^{2}\left(\phi+\mathrm{S}_{\|}\right)} \\
& \text {(system effects) (surface roughness effects) } \\
& +\left(\frac{F}{\langle N\rangle}+\frac{1}{2 K_{s}}\right) \frac{4 z^{2} \tan ^{2} \theta_{T}}{c^{2} \cos ^{2} \phi}\left[\tan ^{2} \theta_{T}+\tan ^{2}\left(\phi+S_{\|}\right)+\frac{\tan ^{2} S_{\perp} \cos ^{2} S_{\|}}{\cos ^{2}\left(\phi+S_{\|}\right)}\right] \\
& \text {(beam curvature effects) (nadir angle and surface slope effects) } \\
& +\frac{4 z^{2}\left(1+\tan ^{2} \theta_{T}\right)^{2}}{c^{2} \cos ^{2} \phi}\left[\tan ^{2}\left(\phi+S_{\|}\right) \operatorname{Var}(\Delta \phi \|)+\frac{\tan ^{2} S_{\perp} \cos ^{2} S_{\|} \cos ^{2} \phi}{\cos ^{2}\left(\phi+S_{\|}\right)} \operatorname{Var}\left(\Delta \phi_{\perp}\right)\right] \\
& \text { (pointing jitter effects) }
\end{aligned}
$$

The photon noise contributions to the range error variance are inversely proportional to $<\mathrm{N}>$, the expected number of detected photons per received pulse. The speckle noise contributions are inversely proportional to $K_{s}$, the ratio of the receiver aperture area to the speckle correlation area. Some of the speckle noise effects can be reduced by increasing $\mathrm{K}_{\mathrm{s}}$ either by increasing the aperture area or the laser divergence (see Eq. (11)). However, some of the speckle noise terms are proportional to $\tan ^{2} \theta_{\mathrm{T}} / \mathrm{K}_{\mathrm{S}}$ and $\tan ^{4} \theta_{\mathrm{T}} / \mathrm{K}_{\mathrm{s}}$. These terms are either independent of $\theta_{\mathrm{T}}$ or proportional to $\tan ^{2} \theta_{T}$. It is not difficult to show by taking the derivative of (19) with respect to $\tan \theta_{\mathrm{T}}$ that speckle errors are minimized when 
Table 2 Range Measurement Errors $\frac{c}{2} \operatorname{Std}\left(T_{p}\right)$

\begin{tabular}{|c|c|c|}
\hline Source & Simplified Formula & Value* \\
\hline Surface roughness & $\frac{\operatorname{Std}(\Delta \xi)}{\sqrt{\langle\mathrm{N}\rangle}}$ & negligible to $\sim 0.6 \mathrm{~m}$ \\
\hline Nadir angle & $\frac{\mathrm{z} \theta_{\mathrm{T}} \tan \phi}{\sqrt{\langle\mathrm{N}\rangle}}$ & $\sim 0.2 \mathrm{~m} @ \phi=5^{\circ}$ \\
\hline Surface slope & $\frac{z \theta_{\mathrm{T}} \tan S}{\sqrt{\langle\mathrm{N}\rangle}}$ & $\begin{array}{l}\sim 0.04 \mathrm{~m} @ S=1^{\circ} \\
\sim 0.2 \mathrm{~m} @ S=5^{\circ} \\
\sim 0.4 \mathrm{~m} @ S=10^{\circ} \\
\sim 1 \mathrm{~m} @ S=30^{\circ}\end{array}$ \\
\hline Pointing jitter & $\mathbf{z S t d}(\Delta \phi) \tan S$ & $\begin{array}{l}\sim 0.18 \mathrm{~m} @ S=1^{\circ} \& \Delta \phi=10 \mu \mathrm{rad} \\
\sim 0.8 \mathrm{~m} @ S=5^{\circ} \& \Delta \phi=10 \mu \mathrm{rad} \\
\sim 1.8 \mathrm{~m} @ S=10^{\circ} \& \Delta \phi=10 \mu \mathrm{rad} \\
\sim 6 \quad \mathrm{~m} @ S=30^{\circ} \& \Delta \phi=10 \mu \mathrm{rad}\end{array}$ \\
\hline
\end{tabular}

$$
\tan \theta_{\mathrm{T}}=\sqrt{2} \frac{\cos S_{\|} \cos \phi}{\cos \left(\phi+S_{\|}\right)} \frac{\operatorname{Std}(\Delta \xi)}{z}
$$

The laser divergence is typically much larger than the value given by (20).

The major ranging error effects $\frac{c}{2} \operatorname{Std}\left(T_{p}\right)$ are listed in Table 2 for the case where $F=1$. Typical values for these errors were computed by assuming $\langle\mathrm{N}\rangle \sim 10^{3}$ and $\mathrm{K}_{\mathrm{s}} \sim 10^{4}$. The surface roughness, nadir angle and surface slope contributions arise because the performance of the centroid estimator is proportional to the received pulse width. Pulse broadening is greatest over rough terrain or when the nadir angle or surface slopes are large. The pointing jitter contribution arises from the bias introduced into the propagation delay when there is a pointing error. Notice from the simplified formulas included in Table 2 that pointing jitter and surface slope contributions are comparable when

$$
\operatorname{Std}(\Delta \phi)=\theta_{\mathrm{T}} / \sqrt{\mathrm{N}}
$$


Table 3 Pulse Width Measurement Errors $\frac{\mathbf{c}}{2} \operatorname{Std}\left(\sigma_{\mathrm{p}}\right)$

\begin{tabular}{|c|c|c|}
\hline Source & Simplified Formula & Value* \\
\hline Surface roughness & $\frac{\operatorname{Std}(\Delta \xi)}{\sqrt{2<N>}}$ & negligible to $-0.4 \mathrm{~m}$ \\
\hline Surface slope & $\frac{\mathrm{z}_{\mathrm{T}} \tan S}{\sqrt{2<\mathrm{N}\rangle}}$ & $\begin{array}{l}\sim 0.2 \mathrm{~m} @ S=5^{\circ} \\
\sim 0.3 \mathrm{~m} @ S=10^{\circ} \\
\sim 0.8 \mathrm{~m} @ S=30^{\circ}\end{array}$ \\
\hline Nadir angle & $\frac{z \theta_{\mathrm{T}} \tan \phi}{\sqrt{2<\mathrm{N}\rangle}}$ & 0.2 m@ $\phi=5^{\circ}$ \\
\hline
\end{tabular}

*All values were computed assuming $\mathrm{z}=1000 \mathrm{~km}, \theta_{\mathrm{T}}=64 \mu \mathrm{rad}$ (i.e., $\left.150 \mu \mathrm{rad} \mathrm{FWHM}\right),\langle\mathrm{N}\rangle=10^{3}$ and $\mathrm{F}=1$.

For $\langle\mathrm{N}\rangle=10^{3}$ and $\theta_{\mathrm{T}}=64 \mu \mathrm{rad}$, we see from (21) that pointing jitter contributions dominate when $\operatorname{Std}(\Delta \phi) \geq 2 \mu \mathrm{rad}$. Pointing jitter is usually the dominant source of range error especially over terrain with large surface slopes. The extreme sensitivity to pointing errors is due to the small laser divergence. Terrain slopes averaged over the footprint can be quite large when the divergence is small. When divergence and hence the footprint are large, the average surface slope within the footprint is usually small, however the roughness can be large in this situation.

Depending on the statistical characteristics of the surface profile, there is an optimum divergence angle which minimizes range error by balancing the surface roughness and the pointing jitter/surface slope contributions.

If we neglect the effects of speckle, the variance of the rms pulse width measurement is given by 


$$
\begin{aligned}
& \operatorname{Var}\left(\sigma_{\mathrm{p}}\right)=\frac{\mathrm{FE}\left(\sigma_{\mathrm{p}}^{2}\right)}{2<\mathrm{N}>} \simeq \frac{\mathrm{F}\left(\sigma_{\ell}{ }^{2}+\sigma_{\mathrm{h}}^{2}\right)}{2<\mathrm{N}>}+\frac{\mathrm{F}}{<\mathrm{N}>} \frac{2 \operatorname{Var}(\Delta \xi) \cos ^{2} S_{\|}}{c^{2} \cos ^{2}\left(\phi+S_{\|}\right)} \\
& \text {(system effects) (surface roughness effects) } \\
& +\frac{F}{<N>} \frac{2 z^{2} \tan ^{2} \theta_{T}}{c^{2} \cos ^{2} \phi}\left[\tan ^{2} \theta_{T}+\tan \left(\phi+S_{\|}\right)+\frac{\tan ^{2} S_{\perp} \cos ^{2} S_{\|}}{\cos ^{2}\left(\phi+S_{\|}\right)}\right] \\
& \text {(beam curvature effects) (nadir angle and surface slope effects) }
\end{aligned}
$$

The performance of the pulse width estimator is proportional to the received pulse width and so the major contributions to the error arise from surface slope and nadir angle effects. Typical values for the pulse width errors $\frac{\mathrm{c}}{2} \operatorname{Std}\left(\sigma_{\mathrm{p}}\right)$ are listed in Table 3 .

\section{SURFACE SLOPE MEASUREMENTS}

For some geophysical applications, the accurate determination of surface slope is of considerable interest. The total slope can be estimated from the measured pulse width. Consider the diagram in Fig. 4a for nadir pointing. The laser footprint diameter is approximately $2 z \tan \theta_{\mathrm{T}} \tan S$. The surface slope is approximately equal to the pulse width divided by the footprint diameter. From Eq. (18) with the nadir angle equal to zero, we have

$$
\frac{c^{2} E\left(\sigma_{\mathrm{p}}^{2}\right)}{4 \mathrm{z}^{2} \tan ^{2} \theta_{\mathrm{T}}}=\tan ^{2} S+\tan ^{2} \theta_{\mathrm{T}}+\frac{\operatorname{Var}(\Delta \xi)}{\mathrm{z}^{2} \tan ^{2} \theta_{\mathrm{T}}}+\frac{\mathrm{c}^{2}\left(\sigma_{\ell}^{2}+\sigma_{\mathrm{h}}^{2}\right)}{4 \mathrm{z}^{2} \tan ^{2} \theta_{\mathrm{T}}} .
$$

The last 3 terms in Eq. (23) are bias terms. The biases related to the laser divergence, laser pulse width and receiver impulse response can be calculated from known system parameters and subtracted from the right-hand side of Eq. (23). The bias related to surface roughness cannot be determined a priori but can be minimized by increasing the beam divergence. Of course, the range bias and error increase with increasing $\theta_{\mathrm{T}}$ (see Eqs. (19) and (20)). When $\mathrm{z}=1000 \mathrm{~km}, \theta_{\mathrm{T}}$ $=64 \mu \mathrm{rad}$ and $\operatorname{Std}(\Delta \xi)=10 \mathrm{~m}$, the slope bias is approximately $9^{\circ}$. The slope bias is less than $1^{\circ}$ when the rms roughness is $1 \mathrm{~m}$. The variance of the slope estimate can be calculated by using Eq. (22). The result for $\phi=0$ is 

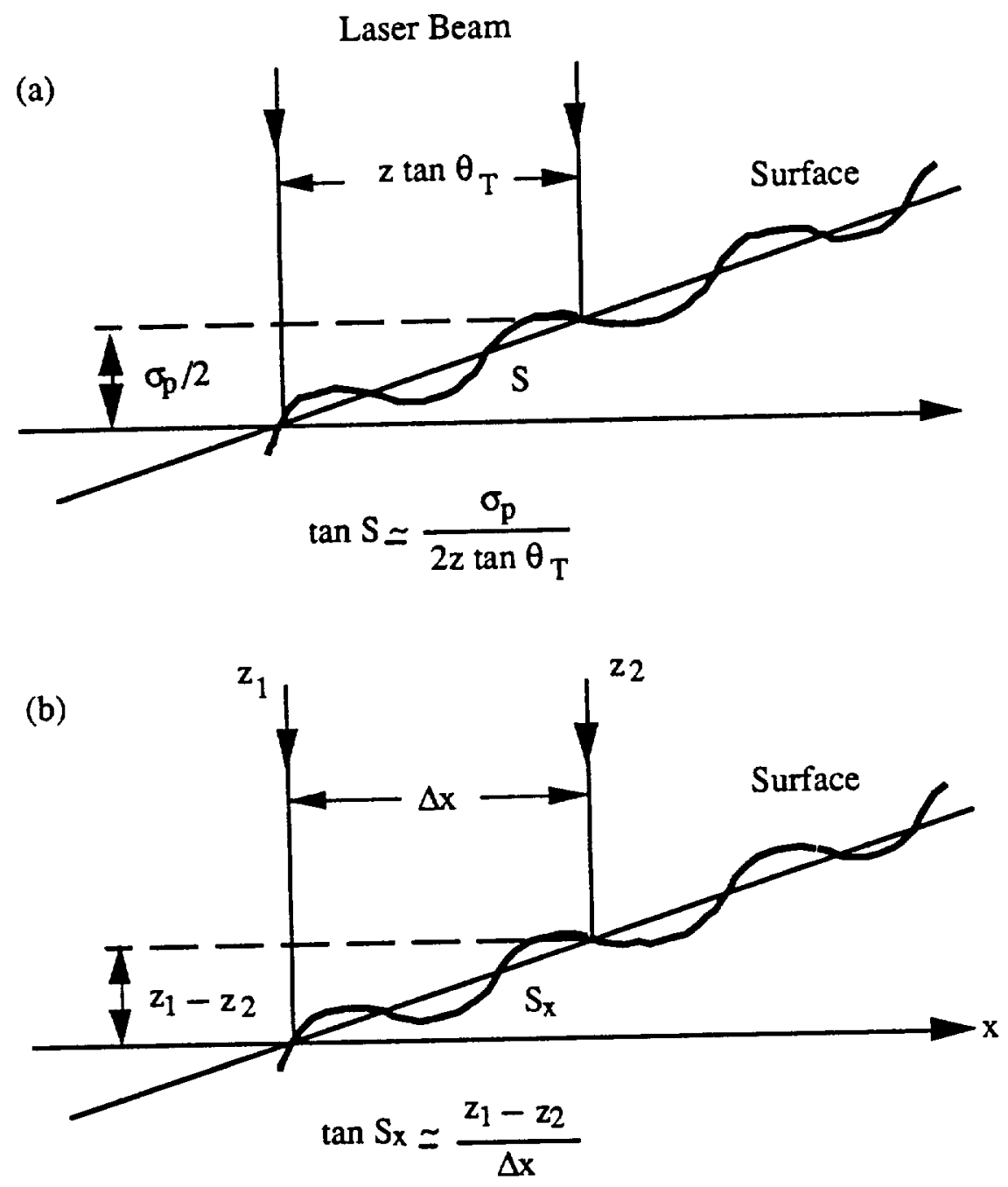

Figure 4. Target and altimeter geometries for surface slope measurements: (a) single pulse technique and (b) double pulse technique.

$$
\operatorname{Var}(\tan S)=\frac{F}{2<N>}\left[\tan ^{2} S+\tan ^{2} \theta_{\mathrm{T}}+\frac{\operatorname{Var}(\Delta \xi)}{z^{2} \tan ^{2} \theta_{T}}\right]
$$

If surface roughness effects are negligible, the slope error reduces to

$$
\operatorname{Std}(\tan S) \simeq \tan S \sqrt{\frac{F}{2<N>}}
$$

and is typically less than $1^{\circ}$.

The average surface slope along the satellite ground track can also be estimated by differencing the range measured with two different laser pulses (see Fig. 4b). 


$$
\tan S_{x}=\frac{z_{1}-z_{2}}{\Delta x}
$$

The slope variance using this method is

$$
\begin{gathered}
\operatorname{Var}\left(\tan S_{\mathrm{x}}\right)=\frac{\operatorname{Var}\left(\mathrm{z}_{1}\right)+\operatorname{Var}\left(\mathrm{z}_{2}\right)}{(\Delta \mathrm{x})^{2}}=\frac{\mathrm{c}^{2} \operatorname{Var}\left(\mathrm{T}_{\mathrm{p}}\right)}{2(\Delta \mathrm{x})^{2}} \simeq \\
\frac{2 \mathrm{~F}}{<\mathrm{N}>(\Delta \mathrm{x})^{2}}\left[\operatorname{Var}(\Delta \xi)+\mathrm{z}^{2} \tan ^{2} \mathrm{~S}\left(\tan ^{2} \theta_{\mathrm{T}}+\operatorname{Var}(\Delta \phi)\right)\right] .
\end{gathered}
$$

This method is potentially very accurate and the error can be as small as $0.1^{\bullet}$ depending on $\Delta x$. However, the horizontal separation of the two measurements must be small enough that the computed slope represents the true slope trend of the surface.

\section{BACKGROUND NOISE, THERMAL NOISE, QUANTIZATION NOISE AND}

The results of the previous sections were derived by neglecting the effects of background noise, quantization noise and sampling effects of the A/D converter (see Fig. 1). The A/D converter model is illustrated in Fig. 5. $A_{k}$ is the current amplitude corresponding to the kth quantization level and $\Delta t$ is the sampling interval or range bin length. $T$ is the total observation interval. If we neglect speckle noise, the mean and variance of the detector current are approximately

$$
\begin{gathered}
\mathrm{E}[\mathrm{i}(\mathrm{t})]=\mathrm{G} \mathrm{h}(\mathrm{t}) *\left[\mathrm{p}(\mathrm{t})+\mu_{\mathrm{b}}\right] \simeq \mathrm{Ge} \mathrm{p}(\mathrm{t})+\mathrm{Ge} \mu_{\mathrm{b}} \\
\operatorname{Var}[\mathrm{i}(\mathrm{t})]=\mathrm{G}^{2} \mathrm{~F} \mathrm{~h}^{2}(\mathrm{t}) *\left[\mathrm{p}(\mathrm{t})+\mu_{\mathrm{b}}\right]+\sigma_{\mathrm{th}}^{2} \cong \frac{\mathrm{G}^{2} \mathrm{Fe}^{2}}{\Delta \mathrm{t}}\left[\mathrm{p}(\mathrm{t})+\mu_{\mathrm{b}}\right]+\sigma_{\mathrm{th}}^{2}
\end{gathered}
$$

where $\mu_{\mathrm{b}}$ is the background noise count rate (photons/sec), $F$ is the excess noise factor of the detector and $\sigma_{\mathrm{th}}{ }^{2}$ is the thermal noise variance. The mean and variance of the quantized current are

$$
\mathrm{E}\left[\mathrm{i}_{\mathrm{q}}(\mathrm{m} \Delta \mathrm{t})\right]=\mathrm{Ge} \mathrm{p}_{\mathrm{q}}(\mathrm{m} \Delta \mathrm{t})+\mathrm{Ge} \mu_{\mathrm{bq}}
$$




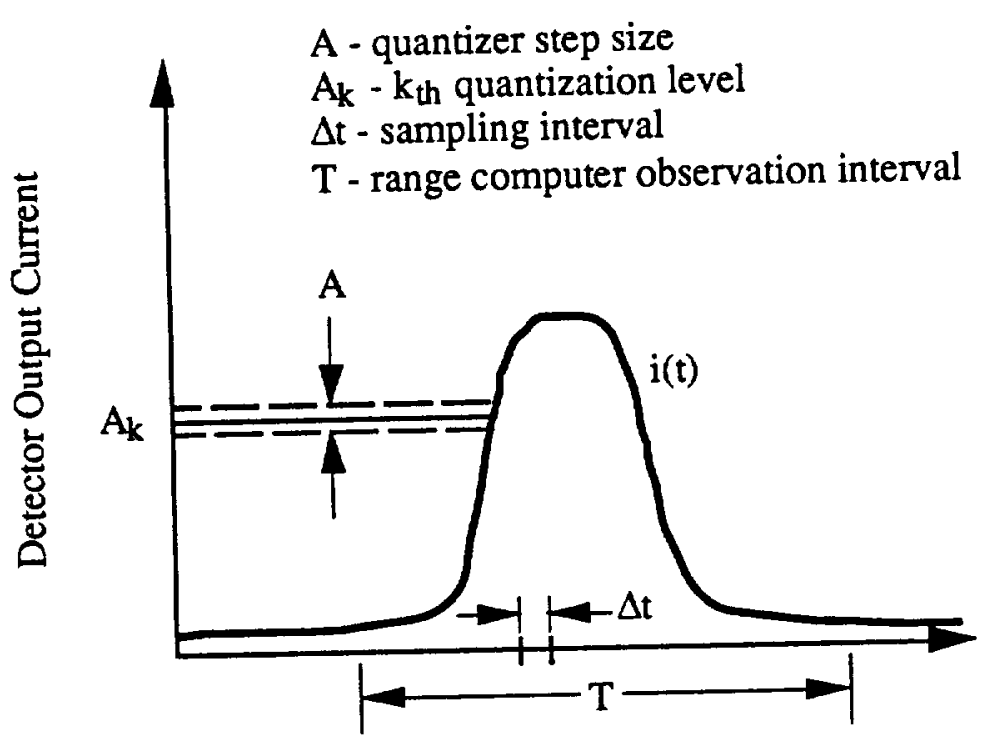

Time

Figure 5. A/D converter model for the laser altimeter.

$$
\operatorname{Var}\left[\mathrm{i}_{\mathrm{q}}(\mathrm{m} \Delta \mathrm{t})\right]=\frac{\mathrm{G}^{2} \mathrm{Fe}^{2}}{\Delta \mathrm{t}}\left[\mathrm{pq}_{\mathrm{q}}(\mathrm{m} \Delta \mathrm{t})+\mu_{\mathrm{bq}}\right]+\sigma_{\mathrm{th}}^{2}+\frac{\mathrm{A}^{2}}{12}
$$

where the subscript $q$ is used to denote the quantized current and pulse amplitudes and $A^{2} / 12$ is the quantization noise variance. Note that (31) was derived by assuming the A/D converter employs a uniform quantizer, i.e. all the current steps are equal $\left(A=A_{k+1}-A_{k}\right.$ for every $\left.k\right)$.

Equations (30) and (31) can now be used with the previous results to estimate the variances of the signal level, propagation delay and pulse width. If we neglect speckle noise, the variances are

$$
\begin{aligned}
& \operatorname{Var}(\mathrm{N}) \simeq \mathrm{F}\left\langle\mathrm{N}>+\frac{\mathrm{T}}{\Delta \mathrm{t}}\left[\mathrm{F} \mu_{\mathrm{b}} \Delta \mathrm{t}+\left(\sigma_{\mathrm{th}} \Delta \mathrm{t} / \mathrm{Ge}\right)^{2}+(\mathrm{A} \Delta \mathrm{t} / \mathrm{Ge})^{2} / 12\right]\right. \\
& \operatorname{Var}\left(\mathrm{T}_{\mathrm{p}}\right) \simeq \frac{\mathrm{F} \sigma_{\mathrm{p}}{ }^{2}}{\langle\mathrm{~N}>}+\frac{\mathrm{T}}{\Delta \mathrm{t}} \frac{\left[\mathrm{F} \mu_{\mathrm{b}} \Delta \mathrm{t}+\left(\sigma_{\mathrm{th}} \Delta \mathrm{t} / \mathrm{Ge}\right)^{2}+(\mathrm{A} \Delta \mathrm{t} / \mathrm{Ge})^{2} / 12\right]}{<\mathrm{N}\rangle^{2}} \frac{\mathrm{T}^{2}}{12}+\frac{\Delta \mathrm{t}^{2}}{12} \\
& \operatorname{Var}\left(\sigma_{\mathrm{p}}{ }^{2}\right) \simeq \frac{2 \mathrm{~F} \sigma_{\mathrm{p}}{ }^{4}}{\langle\mathrm{~N}\rangle}+\frac{\mathrm{T}}{\Delta \mathrm{t}} \frac{\left[\mathrm{F} \mu_{\mathrm{b}} \Delta \mathrm{t}+\left(\sigma_{\mathrm{th}} \Delta \mathrm{t} / \mathrm{Ge}\right)^{2}+(\mathrm{A} \Delta \mathrm{t} / \mathrm{Ge})^{2} / 12\right]}{\langle\mathrm{N}\rangle^{2}}\left(\frac{\mathrm{T}^{4}}{80}-\frac{\mathrm{T}^{2} \sigma_{\mathrm{p}}{ }^{2}}{6}+\sigma_{\mathrm{p}}{ }^{4}\right)+\frac{\Delta \mathrm{t}^{4}}{144}
\end{aligned}
$$

where $\sigma_{\mathrm{p}}^{2}$ is given by (18). 
If $\operatorname{Var}\left(\sigma_{\mathrm{p}}\right) \ll \sigma_{\mathrm{p}}^{2}$ then

$$
\operatorname{Var}\left(\sigma_{\mathrm{p}}\right)=\frac{\operatorname{Var}\left(\sigma_{\mathrm{p}}^{2}\right)}{4 \sigma_{\mathrm{p}}^{2}}
$$

and (34) can be rewritten as

$$
\begin{gathered}
\operatorname{Var}\left(\sigma_{\mathrm{p}}\right)=\frac{\mathrm{F} \sigma_{\mathrm{p}}^{2}}{2<\mathrm{N}>}+\frac{\mathrm{T}}{\Delta \mathrm{t}} \frac{\left[\mathrm{F} \mu_{\mathrm{b}} \Delta \mathrm{t}+\left(\sigma_{\mathrm{th}} \Delta / \mathrm{Ge}\right)^{2}+(\mathrm{A} \Delta \mathrm{t} / \mathrm{Ge})^{2} / 12\right]}{\left\langle\mathrm{N}>^{2}\right.}\left(\frac{\mathrm{T}^{4}}{320 \sigma_{\mathrm{p}}^{2}}-\frac{\mathrm{T}^{2}}{24}+\frac{\sigma_{\mathrm{p}}^{2}}{4}\right) \\
+\frac{\Delta \mathrm{t}^{4}}{576 \sigma_{\mathrm{p}}^{2}} .
\end{gathered}
$$

Notice that the pulse delay and pulse width variances are related to the length of the observation period $\mathrm{T}$ and the sampling interval $\Delta \mathrm{t}$. Because background noise, thermal noise and quantization noise are present in the receiver output even when there is no optical pulse, it is important to limit the interval over which the pulse parameters are computed to just the period when the pulse is present. Equations (33), (34) and (36) were derived by assuming the observation interval was $\left(T_{p}-T / 2, T_{p}+T / 2\right)$. The finite range bin width introduces additional errors that are related to $\Delta \mathrm{t}$. Note that $\sigma_{\mathrm{th}} / \mathrm{Ge}$ and $\mathrm{A} / \mathrm{Ge}$ are the equivalent photon count rates associated with thermal noise and quantization noise.

In a well-designed system the signal level is large compared to background noise so that the dominant error source is photon noise in the detected laser pulse. The background count rate for solar illumination is given by

$$
\mu_{\mathrm{b}}=\mathrm{T}_{\mathrm{a}}^{2} \frac{\eta}{h v}\left[S_{0}(\lambda) \Delta \lambda \pi \mathrm{r}^{2} \tan ^{2}\left(\theta_{\mathrm{FOV}}\right)\right] \frac{\mathrm{A}}{\pi \mathrm{r}^{2}} \beta(\phi)
$$

where

$$
\begin{aligned}
& S_{\mathrm{o}}(\lambda)=\text { solar spectral irradiance measured at the top of the earth's } \\
& \Delta \lambda=\text { atmosphere }\left(\mathrm{Wm}^{-2} \mathrm{~nm}^{-1}\right) \\
& \theta_{\text {FOV }}=\text { receiver optical filter bandwidth }(\mathrm{nm})
\end{aligned}
$$


By comparing (37) and (9) and using (32) - (34) it is not difficult to show that background noise is negligible provided

$$
\mathrm{TS}_{\mathrm{o}}(\lambda) \Delta \lambda \pi \mathrm{r}^{2} \tan ^{2}\left(\theta_{\mathrm{FOV}}\right) \ll \mathrm{E}
$$

where $E$ is the laser pulse energy. Typically the observation interval extends over the full width of the received pulse measured at the $e^{-2}$ points (i.e. $T_{p} \pm 2 \sigma_{p}$ ) and the receiver field-of-view matches the laser divergence angle at the $\mathrm{e}^{-2}$ intensity points so that

$$
\begin{aligned}
& \mathrm{T}=4 \sigma_{\mathrm{p}} \\
& \theta_{\mathrm{FOV}}=2 \theta_{\mathrm{T}}
\end{aligned}
$$

and (38) becomes

$$
16 \pi \mathrm{r}^{2} \theta_{\mathrm{T}^{2}} \sigma_{\mathrm{p}} S_{\mathrm{o}}(\lambda) \Delta \lambda \ll \mathrm{E}
$$

In the visible and near infrared region of the spectrum near dawn and dusk $S_{0} \sim 10^{-2}$ $\mathrm{Wm}^{-2} \mathrm{~nm}^{-1}$. For the case where $\mathrm{r}=400 \mathrm{~km}, \theta_{\mathrm{T}}=1 \mathrm{mrad}, \Delta \lambda=1 \mathrm{~nm}$ and $\sigma_{\mathrm{p}}=10 \mathrm{~ns}$, the lefthand side of (41) is less than $1 \mathrm{mj}$. In this case, background noise will be negligible provided the laser pulse energy is much larger than $1 \mathrm{mj}$. If we use (40) in (37), the background count rate can also be expressed as

$$
\mu_{b}=T_{a}^{2} \frac{\eta}{h v} S_{o}(\lambda) \Delta \lambda \theta T^{2} A \beta(\phi)
$$

Now consider a baseline A/D converter design in which the current step size is selected by assuming the worse case where all the photons are detected in 1 range bin,

$$
\frac{\leq \mathrm{N}\rangle}{2^{\mathrm{n}}}=\frac{\mathrm{A} \Delta \mathrm{t}}{\mathrm{Ge}}
$$


where $\mathrm{n}$ is the number of digitizer bits. We assume the observation interval extends over the full width of the received pulse measured at the $e^{-2}$ points (i.e. $T_{p} \pm 2 \sigma_{p}$ ) so that $T=4 \sigma_{p}$. If we neglect background noise and thermal noise then the variance of $N, T_{p}$ and $\sigma_{p}{ }^{2}$ become

$$
\begin{aligned}
& \operatorname{Var}(\mathrm{N}) \simeq \mathrm{F}<\mathrm{N}>+\frac{1}{3} \frac{\sigma_{\mathrm{p}}}{\Delta \mathrm{t}} \frac{<\mathrm{N}>2}{2^{2 \mathrm{n}}} \\
& \operatorname{Var}\left(\mathrm{T}_{\mathrm{p}}\right) \simeq \frac{\mathrm{F} \sigma_{\mathrm{p}}^{2}}{\langle\mathrm{~N}>}+\frac{4}{9} \frac{\sigma_{\mathrm{p}}}{\Delta \mathrm{t}} \frac{\sigma_{\mathrm{p}}^{2}}{2^{2 \mathrm{n}}}+\frac{\Delta \mathrm{t}^{2}}{12} \\
& \operatorname{Var}\left(\sigma_{\mathrm{p}}{ }^{2}\right)=\frac{2 \mathrm{~F} \sigma_{\mathrm{p}}^{4}}{<\mathrm{N}>}+\frac{23}{45} \frac{\sigma_{\mathrm{p}}}{\Delta \mathrm{t}} \frac{\sigma_{\mathrm{p}}^{4}}{2^{2 \mathrm{n}}}+\frac{\Delta \mathrm{t}^{4}}{144} .
\end{aligned}
$$

The A/D converter should be designed so that the errors associated with sampling and quantization noise are no larger than the errors associated with photon noise. From Eq. (45) we obtain

$$
\begin{gathered}
\Delta t<\left(\frac{12 \mathrm{~F}}{\langle\mathrm{~N}\rangle}\right)^{1 / 2} \sigma_{\mathrm{p}} \sim \sigma_{\mathrm{p}} / 10 \\
2^{2 \mathrm{n}}>\frac{4}{9} \frac{\sigma_{\mathrm{p}}}{\Delta \mathrm{t}} \frac{\langle\mathrm{N}\rangle}{\mathrm{F}}>\frac{2}{9 \sqrt{3}}\left(\frac{<\mathrm{N}>}{\mathrm{F}}\right)^{3 / 2} \sim 2^{12 .}
\end{gathered}
$$

These equations suggest that the A/D converter should be designed so that the sampling interval $\Delta t$ is approximately $1 / 10$ the rms width of the received pulse and the number of digitizer bits is 6 or larger. 


\section{EXPECTED PERFORMANCE CAPABILITIES OF SEVERAL SATELLITE LASER ALTIMETER SYSTEMS}

Several laser altimeters are currently under development by NASA for deployment during the next decade. The most sophisticated of these is the Geodynamic Laser Ranging System (GLRS). GLRS is being developed for the Earth Observing System with a planned launch early in the next century. It includes a Q-switched mode-locked Nd:YAG laser operating at the fundamental $(1064 \mathrm{~nm})$, doubled $(532 \mathrm{~nm})$ and tripled $(355 \mathrm{~nm})$ frequencies. The altimeter channel utilizes the fundamental $1064 \mathrm{~nm}$ wavelength and operates with $150 \mathrm{mj} /$ pulse @ 40 pps. The detector is an avalanche photodiode. The GLRS altimeter will be used to study ground and ice sheet topography, surface roughness and to measure sea state. The major system specifications for the GLRS altimeter are listed in Table 4.

The Lidar In-Space Technology Experiment (LITE) is a shuttle pallet experiment scheduled for launch in late 1993 [Couch et al., 1991]. The system includes a flashlamp pumped Nd:YAG laser operating at the fundamental, doubled and tripled frequencies. The telescope is a $0.95 \mathrm{~m}$ diameter beryllium mirror. The $1064 \mathrm{~nm}$ altimeter channel was designed to study the reflectivity of clouds, land and the ocean. The laser pulse energy is $486 \mathrm{mj} @ 10 \mathrm{pps}$. The range resolution is a rather modest $15 \mathrm{~m}$ which is limited by the $10 \mathrm{MHz}$ waveform digitizer. The major system specifications for LITE are also listed in Table 4. 
Table 4 NASA Spaceborne Laser Altimeters

\begin{tabular}{|c|c|c|c|c|c|}
\hline $\begin{array}{l}\text { Instrument } \\
\text { Planet } \\
\text { NASA Mission } \\
\text { Project Start Date } \\
\text { Launch Date } \\
\text { Mission Duration } \\
\text { Orbital Altitude } \\
\text { Laser Footprint Dia. }\end{array}$ & $\begin{array}{c}\text { LITE } \\
\text { Earth } \\
\text { Shutte } \\
1988 \\
1993 \\
7 \text { days } \\
300 \mathrm{~km} \\
300 \mathrm{~m}\end{array}$ & $\begin{array}{c}\text { TMLA } \\
\text { Earth } \\
\text { Earth Probe } \\
1994 \\
1998 \\
3 \mathrm{yrs} \\
400 \mathrm{~km} \\
200 \mathrm{~m}\end{array}$ & $\begin{array}{l}\text { GLRS } \\
\text { Earth } \\
\text { EOS } \\
1989 \\
2000 \\
5 \mathrm{yrs} \\
705 \mathrm{~km} \\
100 \mathrm{~m}\end{array}$ & $\begin{array}{c}\text { MOLA } \\
\text { Mars } \\
\text { Mars Observer } \\
1989 \\
1992 \\
2 \mathrm{yrs} \\
400 \mathrm{~km} \\
160 \mathrm{~m}\end{array}$ & $\begin{array}{c}\text { LOLA } \\
\text { Moon } \\
\text { Lunar Observer } \\
1994 \\
1998 \\
2 \mathrm{yrs} \\
175 \mathrm{~km} \\
30 \mathrm{~m}\end{array}$ \\
\hline $\begin{array}{l}\text { Wavelength } \\
\text { Energy/pulse } \\
\text { Pulse rate } \\
\text { Pulse width }\end{array}$ & $\begin{array}{c}1064 \mathrm{~nm} \\
486 \mathrm{mj} \\
10 \mathrm{pps}\end{array}$ & $\begin{array}{c}1047 \mathrm{~nm} \\
15 \mathrm{mj} \\
1050 \mathrm{pps}\end{array}$ & $\begin{array}{l}1064 \mathrm{~nm} \\
80 \mathrm{mj} \\
40 \mathrm{pps}\end{array}$ & $\begin{array}{l}1064 \mathrm{~nm} \\
40 \mathrm{mj} \\
10 \mathrm{pps}\end{array}$ & $\begin{array}{l}1064 \mathrm{~nm} \\
10 \mathrm{mj} \\
40 \mathrm{pps}\end{array}$ \\
\hline & $27 \mathrm{~ns}$ & $5 \mathrm{~ns}$ & $5 \mathrm{~ns}$ & $8 \mathrm{~ns}$ & $5 \mathrm{~ns}$ \\
\hline $\begin{array}{l}\quad \text { HW @ } \mathrm{e}^{-1 / 2} \\
\text { Telescope Diameter } \\
\text { Obscuration }\end{array}$ & $\begin{array}{c}250 \mu \mathrm{rad} \\
0.95 \mathrm{~m}\end{array}$ & $\begin{array}{c}125 \mu \mathrm{rad} \\
0.9 \mathrm{~m}\end{array}$ & $\begin{array}{c}35.5 \mu \mathrm{rad} \\
0.6 \mathrm{~m}\end{array}$ & $\begin{array}{c}100 \mu \mathrm{rad} \\
0.5 \mathrm{~m}\end{array}$ & $\begin{array}{c}43 \mu \mathrm{rad} \\
0.5 \mathrm{~m}\end{array}$ \\
\hline $\begin{array}{l}\text { Diameter } \\
\text { Pointing Control } \\
\text { Pointing Jitter } \\
\text { Range Resolution }{ }^{+} \\
\text {Overall Optical }\end{array}$ & $\begin{array}{c}0.31 \mathrm{~m} \\
20 \mathrm{mrad} \\
3 \mathrm{mrad} \\
15 \mathrm{~m}\end{array}$ & $\begin{array}{l}0.25 \mathrm{~m} \\
50 \mu \mathrm{rad} \\
10 \mu \mathrm{rad} \\
0.1 \mathrm{~m}\end{array}$ & $\begin{array}{l}0.15 \mathrm{~m} \\
50 \mu \mathrm{rad} \\
10 \mu \mathrm{rad} \\
0.1 \mathrm{~m}\end{array}$ & $\begin{array}{l}0.12 \mathrm{~m} \\
3 \mathrm{mrad} \\
1 \mathrm{mrad} \\
1.5 \mathrm{~m}\end{array}$ & $\begin{array}{c}0.12 \mathrm{~m} \\
3 \mathrm{mrad} \\
20 \mu \mathrm{rad} \\
0.2 \mathrm{~m}\end{array}$ \\
\hline $\begin{array}{l}\text { Efficiency" } \\
\text { Received Pulse } \\
\text { Statistics }\end{array}$ & $10 \%$ & $20 \%$ & $20 \%$ & $20 \%$ & $20 \%$ \\
\hline $\begin{array}{l}\langle\mathrm{N}\rangle \\
\mathrm{K} \\
\mathrm{SNR}\end{array}$ & $\begin{array}{c}87,000 \\
4.4 \times 10^{5} \\
153\end{array}$ & $\begin{array}{l}2,800 \\
1.1 \times 10^{5} \\
28.2\end{array}$ & $\begin{array}{l}2,200 \\
3,700 \\
23.2\end{array}$ & $\begin{array}{c}4.700 \\
2.1 \times 10^{4} \\
35.5\end{array}$ & $\begin{array}{c}6,200 \\
3,800 \\
34.8\end{array}$ \\
\hline
\end{tabular}

${ }^{+}$Range bin length $\Delta z=c \Delta t / 2$

*Includes APD quantum efficiency ( $-50 \%)$

The Mars Observer Laser Altimeter (MOLA) is currently in the final testing phase and will be launched in 1992. MOLA is designed primarily to map the topography of Mars but will also provide some information on surface roughness. The altimeter includes a $40 \mathrm{mj} / \mathrm{pulse}, 10 \mathrm{pps}$ $\mathrm{Nd}$ :YAG operating at $1064 \mathrm{~nm}$ and a $0.5 \mathrm{~m}$ diameter telescope. LOLA, the Lunar Observer Laser Altimeter, is essentially an upgraded version of MOLA which is planned for launch in 1998 to map the lunar topography. The system specifications for both MOLA and LOLA are listed in Table 4. 
The Topographic Mapping Laser Altimeter (TMLA) is designed specifically to measure land and ice surface elevations globally. TMLA is envisioned as a small dedicated satellite of the Earth Probe class and is planned for launch in a polar sun-synchronous orbit in 1998. To obtain high resolution coverage, the Nd:YLF laser array will operate at $15 \mathrm{mj} /$ pulse @ $1050 \mathrm{pps}$. The pulse length is $5 \mathrm{~ns}$. The TMLA system specifications are summarized in Table 4.

To evaluate the performances of these altimeters it is necessary to make some assumptions about the target characteristics. For simplicity we assume a nominal value of 0.3 for the diffuse reflectivity of the earth, moon and Mars. At zenith for excellent visibility, the 1-way transmission through the earth's atmosphere is approximately 0.95 at $1064 \mathrm{~nm}$. To be conservative we assume the 1-way atmospheric transmission is 0.7 for the earth and 1.0 for the moon and Mars. The mean detected photon count per pulse is listed in Table 4 for each altimeter. Also listed is the signal-to-noise ratio (SNR) which is defined as

$$
\mathrm{SNR}=\langle\mathrm{N}\rangle / \mathrm{Std}(\mathrm{N})=\left(\frac{\mathrm{F}}{\langle\mathrm{N}\rangle}+\frac{1}{\mathrm{~K}_{\mathrm{s}}}\right)^{-1 / 2}
$$

The excess noise factor of the APD was assumed to be 3.5 for each system. LITE has the highest SNR, primarily because the large pulse energy and telescope provide a very high signal level and the large laser divergence minimizes speckle noise.

Ranging accuracy is influenced considerably by the terrain slope and surface roughness. Representative terrain statistics for the earth's surface are listed in Table 5. These data were obtained by Harding et al. [1991] by analyzing digital terrain elevation data with $90 \mathrm{~m}$ spatial resolution. The slope values correspond to the mean north-south and east-west surface slopes. The $\Sigma 50 \%$ and $\Sigma 90 \%$ entries refer to the surface slope and RMS roughness values representing the $50 \%$ and $90 \%$ cumulative distribution levels. For example, $50 \%$ of the north-south and eastwest surface slopes in high relief areas were less than $13.6^{\circ}$ while $90 \%$ were less than $28.2^{\circ}$. 
Table 5 Representative Terrain Statistics

\begin{tabular}{|c|c|c|c|c|c|c|}
\hline \multirow[t]{2}{*}{ Relief } & \multicolumn{2}{|l|}{ Geomorphic Features } & \multicolumn{2}{|c|}{ Surface Slope } & \multicolumn{2}{|c|}{ RMS Roughness } \\
\hline & & & $\Sigma 50 \%$ & $\Sigma 90 \%$ & $\Sigma 50 \%$ & $\Sigma 90 \%$ \\
\hline Low & $\begin{array}{l}\text { Glaciated Continental Shield } \\
\text { Shallowly Incised Drainage } \\
\text { Ice Cap } \\
\text { Moderately Incised Drainage }\end{array}$ & & $\begin{array}{l}0.55^{\circ} \\
0.85^{\circ} \\
0.90^{\circ} \\
0.95^{\circ}\end{array}$ & $\begin{array}{l}1.6^{\circ} \\
2.7^{\circ} \\
4.3^{\circ} \\
3.2^{\circ} \\
\end{array}$ & $\begin{array}{l}0.5 \mathrm{~m} \\
0.9 \mathrm{~m} \\
0.3 \mathrm{~m} \\
1.4 \mathrm{~m}\end{array}$ & $\begin{array}{l}0.8 \mathrm{~m} \\
1.9 \mathrm{~m} \\
1.0 \mathrm{~m} \\
3.1 \mathrm{~m}\end{array}$ \\
\hline & & mean & $0.81^{\circ}$ & $3.0^{\circ}$ & $0.8 \mathrm{~m}$ & $1.7 \mathrm{~m}$ \\
\hline Moderate & $\begin{array}{l}\text { Quaternary Volcanic Complexes } \\
\text { Normal-Faulted Rift Graben } \\
\text { Deeply Incised Drainage } \\
\text { Fold and Thrust Orogenic Belt }\end{array}$ & & $\begin{array}{l}1.0^{\circ} \\
1.1^{\circ} \\
4.8^{\circ} \\
3.2^{\circ} \\
\end{array}$ & $\begin{array}{r}6.0^{\circ} \\
5.6^{\circ} \\
21.2^{\circ} \\
17.0^{\circ} \\
\end{array}$ & $\begin{array}{l}1.6 \mathrm{~m} \\
1.2 \mathrm{~m} \\
5.3 \mathrm{~m} \\
4.0 \mathrm{~m} \\
\end{array}$ & $\begin{array}{r}5.8 \mathrm{~m} \\
4.7 \mathrm{~m} \\
14.1 \mathrm{~m} \\
11.1 \mathrm{~m}\end{array}$ \\
\hline & & mean & $2.5^{\circ}$ & $12.5^{\circ}$ & $3.0 \mathrm{~m}$ & $8.9 \mathrm{~m}$ \\
\hline High & Convergent Mountain Front & & $13.6^{\circ}$ & $28.2^{\circ}$ & $6.3 \mathrm{~m}$ & $14.5 \mathrm{~m}$ \\
\hline
\end{tabular}

Table 6 Altimeter Performance at Nadir for Low Relief Terrain Surface Slope $=0.8^{\circ}$ RMS Roughess $=0.8 \mathrm{~m}$

\begin{tabular}{|l|c|c|c|c|c|}
\hline Instrument & LITE & TMLA & GLRS & MOLA & LOLA \\
\hline RMS Received Pulse Length & $\mathbf{4 7 0}$ & 32 & 32 & 67 & \\
System Effects (cm) & $\mathbf{2}$ & $\mathbf{0 . 6}$ & 0.09 & 0.4 & $\mathbf{3 2}$ \\
Beam Curvature (cm) & 80 & 80 & $\mathbf{8 0}$ & $\mathbf{8 0}$ & $\mathbf{8 0}$ \\
Surface Roughness (cm) & 150 & $\mathbf{9 9}$ & 49 & 79 & 15 \\
Surface Slope (cm) & 500 & 130 & 100 & 130 & 90 \\
Total (cm) & & & & & \\
\hline RMS Range Error & 430 & 3.1 & 3.2 & 43 & 5.8 \\
System Effects (cm) & $\mathbf{1 7 8 0}$ & $\mathbf{7 . 9}$ & $\mathbf{1 4}$ & $\mathbf{7 9 0}$ & $\mathbf{6 . 9}$ \\
Pointing Jitter (cm) & 0.52 & 2.8 & 3.5 & 2.3 & 2.3 \\
Surface Roughness (cm) & 0.95 & 3.5 & 2.0 & 2.2 & 0.4 \\
Surface Slope (cm) & 1830 & 9.6 & 15 & 790 & 9.3 \\
Total (cm) & & & & & \\
\hline RMS Pulse Length Error & $\mathbf{1 8 8}$ & 0.8 & 0.9 & $\mathbf{7 . 3}$ & 0.57 \\
System Effects (cm) & 0.36 & 2.0 & $\mathbf{2 . 3}$ & 1.5 & $\mathbf{1 . 3}$ \\
Surface Roughness (cm) & 0.66 & $\mathbf{2 . 5}$ & 1.4 & 1.5 & 0.25 \\
Surface Slope (cm) & 188 & 3.3 & 2.8 & 7.6 & 1.4 \\
Total (cm) & & & & & \\
\hline
\end{tabular}


Table 7 Altimeter Performance at Nadir for Medium Relief Terrain Surface Slope $=2.5^{\circ}$ RMS Roughess $=3.0 \mathrm{~m}$

\begin{tabular}{|c|c|c|c|c|c|}
\hline Instrument & LITE & TMLA & GLRS & MOLA & LOLA \\
\hline $\begin{array}{l}\text { RMS Received Pulse Length } \\
\text { System Effects }(\mathrm{cm}) \\
\text { Beam Curvature }(\mathrm{cm}) \\
\text { Surface Roughness }(\mathrm{cm}) \\
\text { Surface Slope }(\mathrm{cm}) \\
\text { Total }(\mathrm{cm})\end{array}$ & $\begin{array}{c}470 \\
2 \\
300 \\
460 \\
720\end{array}$ & $\begin{array}{l}32 \\
0.6 \\
300 \\
310 \\
430\end{array}$ & $\begin{array}{c}32 \\
0.09 \\
300 \\
150 \\
340\end{array}$ & $\begin{array}{l}67 \\
0.4 \\
300 \\
250 \\
400\end{array}$ & $\begin{array}{c}32 \\
0.03 \\
300 \\
46 \\
310\end{array}$ \\
\hline $\begin{array}{l}\text { RMS Range Errors } \\
\text { System Effects }(\mathrm{cm}) \\
\text { Pointing Jitter }(\mathrm{cm}) \\
\text { Surface Roughness }(\mathrm{cm}) \\
\text { Surface Slope }(\mathrm{cm}) \\
\text { Total }(\mathrm{cm})\end{array}$ & $\begin{array}{c}430 \\
5600 \\
2 \\
3 \\
5600\end{array}$ & $\begin{array}{l}3.1 \\
25 \\
11 \\
11 \\
30\end{array}$ & $\begin{array}{r}3.2 \\
44 \\
13 \\
6.4 \\
46\end{array}$ & $\begin{array}{c}43 \\
2500 \\
8.4 \\
6.8 \\
2500\end{array}$ & $\begin{array}{l}5.8 \\
22 \\
8.6 \\
1.2 \\
24\end{array}$ \\
\hline $\begin{array}{l}\text { RMS Pulse Length Errors } \\
\text { System Effects }(\mathrm{cm}) \\
\text { Surface Roughness }(\mathrm{cm}) \\
\text { Surface Slope }(\mathrm{cm}) \\
\text { Total }(\mathrm{cm})\end{array}$ & $\begin{array}{l}130 \\
1.3 \\
2.1 \\
130\end{array}$ & $\begin{array}{r}0.8 \\
7.5 \\
7.7 \\
11\end{array}$ & $\begin{array}{l}0.9 \\
8.5 \\
4.4 \\
9.6\end{array}$ & $\begin{array}{c}2.7 \\
5.8 \\
4.8 \\
8\end{array}$ & $\begin{array}{c}0.54 \\
5 \\
0.8 \\
5.1\end{array}$ \\
\hline
\end{tabular}

Table 8 Altimeter Performance at Nadir for High Relief Terrain Surface Slope $=13.6^{\circ}$ RMS Roughess $=6.3 \mathrm{~m}$

\begin{tabular}{|l|c|c|c|c|c|}
\hline \multicolumn{1}{|c|}{ Instrument } & LITE & TMLA & GLRS & MOLA & LOLA \\
\hline RMS Received Pulse Length & 470 & 32 & 32 & 67 & 32 \\
System Effects (cm) & 2 & 0.6 & 0.09 & 0.4 & 0.03 \\
Beam Curvature (cm) & 630 & 630 & 630 & 630 & $\mathbf{6 3 0}$ \\
Surface Roughness (cm) & $\mathbf{2 6 0 0}$ & $\mathbf{1 7 0 0}$ & $\mathbf{8 6 0}$ & $\mathbf{1 4 0 0}$ & 260 \\
Surface Slope (cm) & 2700 & 1800 & 1100 & 1500 & 680 \\
Total (cm) & & & & & \\
\hline RMS Range Errors & 430 & 3.1 & 3.2 & 43 & 5.8 \\
System Effects (cm) & $\mathbf{3 1 0 0 0}$ & $\mathbf{1 4 0}$ & $\mathbf{2 4 0}$ & $\mathbf{1 4 0 0 0}$ & $\mathbf{1 2 0}$ \\
Pointing Jitter (cm) & 4.1 & 22 & 27 & 18 & 18 \\
Surface Roughness (cm) & 17 & 61 & 36 & 38 & 6.8 \\
Surface Slope (cm) & 31000 & 150 & 240 & 14000 & 19 \\
Total (cm) & & & & & \\
\hline RMS Pulse Length Errors & 35 & 0.8 & 0.9 & 1.4 & 0.54 \\
System Effects (cm) & 2.8 & 16 & 18 & 12 & 11 \\
Surface Roughness (cm) & 12 & $\mathbf{4 3}$ & $\mathbf{2 4}$ & $\mathbf{2 6}$ & $\mathbf{4 . 3}$ \\
Surface Slope (cm) & 37 & 46 & 30 & 29 & 12 \\
Total (cm) & & & & & \\
\hline
\end{tabular}


The $\Sigma 50 \%$ statistics in Table 5 were used to compute the RMS received pulse lengths $\mathrm{c} / 2\left[\mathrm{E}\left(\sigma_{\mathrm{p}}{ }^{2}\right)\right]^{1 / 2}$ and the single-shot range errors $\mathrm{c} / 2 \operatorname{Std}\left(\mathrm{T}_{\mathrm{p}}\right)$ and pulse length errors $\mathrm{c} / 2 \operatorname{Std}\left(\sigma_{\mathrm{p}}\right)$ for the LITE, TMLA, GLRS, MOLA and LOLA altimeters. The results for low, medium and high relief terrain are tabulated respectively in Tables 6,7 and 8. The simplified formulas used to compute the data in Tables 6-8 are listed in Table 9.

The data in Tables 6-8 show that pulse broadening is dominated primarily by terrain effects. For low and medium relief terrain, surface roughness effects are the most significant for GLRS, MOLA and LOLA while surface slope effects are most significant for TMLA because of its larger divergence angle. System effects, viz. the relatively slow $10 \mathrm{MHz}$ waveform digitizer, make the largest contribution to pulse broadening for the LITE altimeter over low and medium relief terrain. For high relief terrain, slope effects make the largest contribution to pulse broadening for the LITE, TMLA, GLRS and MOLA altimeters. For LOLA, slope effects are not as important as roughness effects because the orbital altitude is low and the laser divergence is small.

Because the signal levels for all five altimeters are quite high, pulse broadening contributions to the range error are relatively small and typically only a few $\mathrm{cm}$. The major source of range error is pointing jitter. Pointing jitter range errors are most severe over high relief terrain where the slopes are large. Because pointing jitter is large for LITE ( $3 \mathrm{mrad}$ ) and MOLA ( $1 \mathrm{mrad})$, the single-shot range error for these systems varies between about 1 and $30 \mathrm{~m}$ depending on the terrain statistics. The single-shot range error for TMLA, GLRS and LOLA are only $10-50 \mathrm{~cm}$ over low and medium relief terrain because the pointing stability for these altimeters is $100 \mu \mathrm{rad}$ or less. Terrain effects are the major source of errors in the single-shot pulse width measurements for TMLA, GLRS, MOLA and LOLA while the waveform digitizer resolution is the major source of pulse width errors for LITE. 
Table 9 Simplified Formulas Used to Compute the Entries in Tables 6,7 and 8

\begin{tabular}{|c|c|}
\hline \multicolumn{2}{|c|}{ RMS Received Pulse Length $\quad c / 2\left[E\left(\sigma_{p}^{2}\right)\right]^{1 / 2}$} \\
\hline System Effects & $c / 2\left(\sigma_{\ell}{ }^{2}+\Delta t^{2} / 12\right)^{1 / 2}$ \\
\hline Beam Curvature & $z \tan ^{2} \theta_{T}$ \\
\hline Surface Roughness & $\operatorname{Std}(\Delta \xi)$ \\
\hline Surface Slope & $\sqrt{2} z \tan \theta_{\mathrm{T}} \tan S$ \\
\hline \multicolumn{2}{|c|}{ RMS Range Error $\quad c / 2 \operatorname{Std}\left(T_{p}\right)$} \\
\hline System Effects & $c / 2\left[\frac{\mathrm{F}}{\langle\mathrm{N}\rangle}\left(\sigma_{l}{ }^{2}+\Delta \mathrm{t}^{2} / 12\right)+\Delta \mathrm{t}^{2} / 12\right]^{1 / 2}$ \\
\hline Pointing Jitter & $\sqrt{2} \mathrm{z} \tan S \operatorname{Std}(\Delta \phi)$ \\
\hline Surface Roughness & $\left(\frac{\mathrm{F}}{\langle\mathrm{N}\rangle}+\frac{1}{\mathrm{~K}_{\mathrm{s}}}\right)^{1 / 2} \operatorname{Std}(\Delta \xi)$ \\
\hline Surface Slope & $\left(\frac{F}{<N>}+\frac{1}{2 K_{s}}\right)^{1 / 2} \sqrt{2} z \tan \theta_{T} \tan S$ \\
\hline \multicolumn{2}{|c|}{ RMS Pulse Length Error $\quad$ c/2 Std $\left(\sigma_{\mathrm{p}}\right)$} \\
\hline System Effects & $c / 2\left[\frac{\mathrm{F}}{2<\mathrm{N}>}\left(\sigma_{\ell}{ }^{2}+\Delta \mathrm{t}^{2} / 12\right)+\frac{\Delta \mathrm{t}^{4}}{576 \mathrm{E}\left(\sigma_{\mathrm{p}}^{2}\right)}\right]^{1 / 2}$ \\
\hline Surface Roughness & $\left(\frac{\mathrm{F}}{2<\mathrm{N}>}\right)^{1 / 2} \operatorname{Std}(\Delta \xi)$ \\
\hline Surface Slope & $\left(\frac{F}{\langle N\rangle}\right)^{1 / 2} z \tan \theta_{\mathrm{T}} \tan S$ \\
\hline
\end{tabular}

\section{CONCLUSIONS}

Satellite laser altimeters are capable of making important contributions to our knowledge of the topography of the earth and planets. Surface elevations, slopes and roughness can be measured with high precision and accuracy. Well designed systems are capable of achieving single-shot ranging accuracies of a few centimeters to a few meters depending on the terrain characteristics. Excellent signal levels can be obtained using diode-pumped solid state lasers such as Nd:YAG with pulse energies of a few tens of mj and telescope diameters of a few tens of 
$\mathrm{cm}$. Ranging accuracy is critically dependent on the pointing accuracy and stability of the altimeter especially over high relief terrain where the surface slopes are large. At typical orbital altitudes of several hundred $\mathrm{km}$, single-shot range accuracies of a few $\mathrm{cm}$ can be achieved only when the pointing jitter is on the order of $10 \mu \mathrm{rad}$ or less. Of course ranging accuracy can be improved through pulse averaging.

For earth observations, perhaps the most important application for laser altimeters is the measurement of the Greenland and Antarctic ice sheets. Knowledge of the seasonal and long term changes in ice sheet volume can play a significant role in testing and validating global climate models. Ranging accuracies of a few tens of $\mathrm{cm}$ or better are required for this application. Over the oceans, laser altimeters can also be used to measure sea state and surface wind speeds, while accurate measurements of surface roughness and topography over land have numerous applications in the geological sciences.

Acknowledgements: The author gratefully acknowledges the many helpful discussions with James B. Abshire and Jack L. Bufton at NASA Goddard. The work was funded by NASA Grant NSG-5049.

\section{REFERENCES}

J. B. Abshire, S. S. Manizack, W. H. Schaefer, R. K. Zimmerman, J. S. Chitwood and J. C. Caldwell, Design and performance of the receiver for the Mars Observer Laser Altimeter, Prof. Conf. Lasers Electro-Opt., 10, 520-521, 1991.

J. B. Abshire and J. F. McGarry, Two-color short-pulse laser altimeter measurements of ocean surface backscatter, Applied Optics, 26, 1304-1311, 1987.

J. L. Bufton, Laser altimetry measurements from aircraft and spacecraft, Proc. IEEE, 77, 463$477,1989$.

J. L. Bufton, J. B. Garvin, J. F. Cavanaugh, L. Ramos-Izquierdo, T. D. Clem and W. B. Krabill, Airforne lidar profiling of surface topography, Opt. Engrg., 30, 72-78, 1991.

J. L. Bufton, J. E. Robinson, M.D. Feriano and F. S. Flatow, Satellite laser altimeter for measurement of ice sheet topography, IEEE Trans. Geosci. Rem. Sens., GE-20, 544-549, 1982. 
S. C. Cohen, J. J. Degnan, J. L. Bufton, J. B. Garvin and J. B. Abshire, The geoscience laser altimetry/ranging system, IEEE Trans. Geosci. Rem. Sens., GE-25, 581-592, 1987.

R. H. Couch, C. W. Rowland, K. S. Ellis, M. P. Blythe, C. P. Regan, M. R. Koch, C. W. Antill, W. L. Kitchen, J. W. Cox, J. F. DeLorne, S. K. Crockett, R. W. Remus, J. C. Casas and W. H. Hunt, Lidar In-Space Technology Experiment (LITE): NASA's first in-space lidar system for atmospheric research, Opt. Engrg., 30, 88-95, 1991.

C. S. Gardner, Correction of laser tracking data for the effects of horizontal refractivity gradients, Applied Optics, 16, 2427-2432, 1977.

C. S. Gardner, Target signatures for laser altimeters: An analysis, Applied Optics, 21, 448-453, 1982.

J. B. Garvin, J. L. Bufton, W. B. Krabill, T. D. Clem and C. C. Schnetzler, Airborne laser altimetry of craterform structures, submitted to IEEE Trans. Geosci. Rem. Sens., 1991.

D. J. Harding, J. J. Frawley, and J. L. Bufton, Satellite laser altimetry of terrestrial-topography: vertical accuracy as a function of surface slope and roughness, J. Geophys. Res., submitted, 1991.

W. M. Kaula, G. Schubert, R. E. Lingenfelter, W. L. Sjogren, and W. R. Wollenhaupt, Apollo laser altimetry and inferences as to lunar structure, Geochim. Cosmochim. Acta., 38, Suppl. 5, 3049-3058, 1974.

B. M. Tsai and C. S. Gardner, Remote sensing of sea state using laser altimeters, Applied Optics, 21, 3932-3940, 1982. 




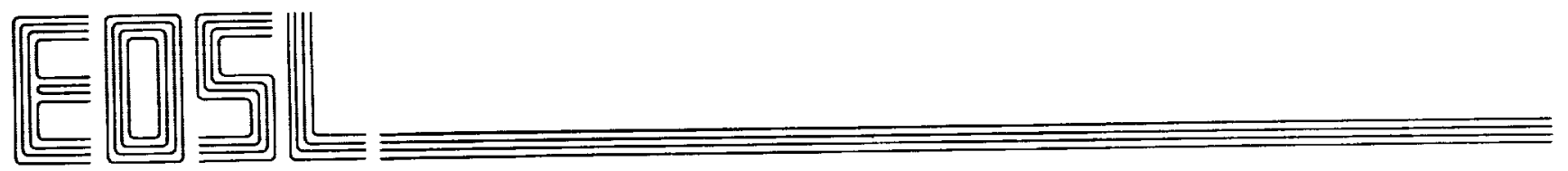

